\title{
Comparing Three Different Three-dimensional Scaffolds for Bone Tissue Engineering: An in vivo Study
}

\author{
${ }^{1}$ Mansour Rismanchian, ${ }^{2}$ Saeid Nosouhian, ${ }^{3}$ Sayed Mohammad Razavi, ${ }^{4}$ Amin Davoudi, ${ }^{5}$ Hamidreza Sadeghiyan
}

\begin{abstract}
Introduction: Three-dimensional Scaffold structure of synthetic biomaterials with their interconnected spaces seem to be a safe and effective option in supporting bone regeneration. The aim of this animal study was to compare the effectiveness of three different biocompatible scaffolds: bioglass (BG), demineralized bone matrix (DBM) and forstrite (FR).
\end{abstract}

Materials and methods: Four healthy dogs were anesthetized and the first to fourth premolars were extracted atraumatically in each quadrant. After healing, linear incision was prepared from molar to anterior segment and 4 defects in each quadrant (16 defects in each dog) were prepared. Scaffold blocks of BG, DBM and FR were resized according to size of defects and placed in the 12 defects randomly, 4 defects remained as control group. The dogs were sacrificed in 4 time intervals $(15,30,45$ and 60 days after) and the percentage of different types of regenerated bones (lamellar and woven) and connective tissue were recorded in histological process. The data were analyzed by one-way ANOVA and post hoc using SPSS software Ver. 15 at significant level of 0.05 .

Results: In day 30th, although the amount of regenerated lamellar bone in control, DBM and BG Scaffold $(22.37 \pm 3.44$; $21.46 \pm 1.96 ; 21.21 \pm 0.96$ ) were near to each, the FR Scaffold provided the highest amount of lamellar $(29.71 \pm 7.94)$ and woven bone (18.28 \pm 2.35$)$. Also, FR Scaffold showed significant difference with BG $(p=0.026)$ and DBM Scaffolds $(p=0.032)$ in regenerated lamellar bone.

Conclusion: We recommend paying more attention to FR Scaffold as a biomaterial, but it is better to be compared with other nano biomaterials in future studies.

Keywords: Bioglass, Bone regeneration, Demonetized bone matrix, Forstrite, Scaffold.

\footnotetext{
1,2Department of Prosthodontics, Dental Implant Research Centre, School of Dentistry, Isfahan University of Medical Sciences, Isfahan, Iran

${ }^{3}$ Department of Oral and Maxillofacial Pathology, Dental Implant Research Centre, School of Dentistry, Isfahan
} University of Medical Sciences, Isfahan, Iran

${ }^{4}$ Department of Dentistry, Dental Students Research Centre School of Dentistry, Isfahan University of Medical Sciences Isfahan, Iran

${ }^{5}$ Department of Medicine, Medician Student Research Centre School of Medicine, Isfahan University of Medical Sciences Isfahan, Iran

Corresponding Author: Saeid Nosouhian, Assistant Professor, Department of Prosthodontics, Dental Implant Research Centre, School of Dentistry, Isfahan University of Medical Sciences, Isfahan, Iran, e-mail:nosouhian@dnt.mui.ac.ir
How to cite this article: Rismanchian M, Nosouhian S, Razavi SM, Davoudi A, Sadeghiyan H. Comparing Three Different Threedimensional Scaffolds for Bone Tissue Engineering: An in vivo Study. J Contemp Dent Pract 2015;16(1):25-30.

Source of support: Nil

Conflict of interest: None

\section{INTRODUCTION}

Due to trauma, tumors, or degenerative disease bone or massive tissue might be lost and reconstruction requires sufficient bone with acceptable quality and quantity. ${ }^{1,2}$ From another view, the optimum goal of periodontal treatments is the regeneration of lost bone and periodontium. ${ }^{3}$ Nowadays many patients are discovering a hope for their jaws to be reconstructed by substitutes with osseous structures. ${ }^{4}$

Autogenously bone grafts are claimed to be the optimum choice for reconstructing bone defects. However, limited bone stock, imposing surgical intervention, and complications at the donor site are some of the major obstacles of this technique. ${ }^{2,5}$ Allogeneic grafts are another tested alternatives which are including as irradiated bone from cadavers (bone mineral from bone banks) and demineralized bone matrix (bone mineral dissolved away by using acids), but immunological responses are probable to happen. ${ }^{6}$

Biocompatibility, bio-restorability and osteogenicity are some the characteristics of an ideal bone substitute. ${ }^{7}$ To accomplish the mentioned properties, synthetic biocompatible bone substitutions have been introduced. They seem to propose a safe and effective option in procedures like filling of fracture defects, complete joint revision surgery and spine fusion but still there is some doubts. ${ }^{7,8}$ They consisted of calcium, phosphate, ceramics, and organic materials which can enhance a stable situation for appropriate bone response and reconstructions. ${ }^{9}$ It is stated that they are appropriate for repairing small defects, not extended bone ones. ${ }^{10}$

The examples are bioactive glass and calcium phosphate ceramics such as hydroxyapatite, and tricalcium phosphate or biphasic calcium phosphate. ${ }^{11}$

In 1971, bioactive glass (BG) first was introduced as a biocompatible material for repairing bone defects. ${ }^{12}$ 
Since then, many studies have proved the capability of BG in promoting osseintegration and forming new bone in defects. ${ }^{13-15}$ It's well surface modifications induce the osteoblast to generate an amorphous calcium phosphate layer which can turn to a biological hydroxycarbonate apatite phase and durable interfacial bonding. ${ }^{12}$ Gatti et $\mathrm{al}^{16}$ managed a study to evaluate the clinical use of BG in treating dental extraction sites before loading implants. The results manifested existence of new bone formation and biodegradation of the glass.

3D Scaffold structure form of these synthetic materials opened a fabulous technique in bone and tissue engineering. They provide a porous and interconnected spaces with sufficient room for migration and adhesion of cells, and finally ingrowth of new bone tissue. ${ }^{17}$ An ideal Scaffold must be able to share loads with surrounded bone. This cannot be achieved if they were brittle, specially when the bone defect is subjected to cyclic loads. ${ }^{18}$ Chen et $\mathrm{al}^{19}$ claimed that BG Scaffolds possess the essential features for bone tissue regenerating as they are biodegradable and support temporary mechanical function.

Forstrite $\left(\mathrm{Mg}_{2} \mathrm{SiO}_{4}\right)(\mathrm{FR})$ is another well biocompatible nanocomposite with better bonding strength, fracture toughness; specially in combination with Polycaprolactone which results in a Scaffold structure appropriate for bone tissue regeneration. ${ }^{20-23} \mathrm{~F}$ Tavangarian RE conducted a study about bioactivity of Forstrite, the result revealed that mechanical properties of Forstrite tolerated implant material loads, perfectly. ${ }^{20}$

Collagen and demineralized bone matrix (DBM) Scaffolds have their advocates, too. They can stimulate osteoinductive factors including bone morphogenetic proteins and transforming growth factor- $\alpha$ (TGF- $\alpha$ ) for new bone regeneration. ${ }^{24-26}$

Based on above information, the aim of this study was to compare the efficacy of BG, FR and DBM based Scaffolds in supporting new bone formation.

\section{MATERIALS AND METHODS}

\section{Ethics}

This study was approved by the animal department of Torabinejad Dental Research Center and local ethical committee of Isfahan University of medical science.

\section{Surgical Procedure}

In this prospective animal study, four healthy male dogs (Persian race) aged 1-4 and weighed 32 to $46 \mathrm{~kg}$ were included. The dogs were anesthetized initially with 10 $\mathrm{mg} / \mathrm{kg}$ Ketamine (Ketamine HCL, Alfasan, Woerden, Holland) and $0.15 \mathrm{mg} / \mathrm{kg}$ Rampone under aseptic condition and maintained under general anesthesia by
5\% Halothane (Halothane, Bp, Nicholas Piramal India Limited, India) and $\mathrm{N}_{2} \mathrm{O}$. First to fourth premolars were extracted without severe trauma in each quadrant and surrounding bone was tried to be preserved, according to Helsinki declaration. Parallel periapical radiographs were taken with XCP film holders (Rinn Co., USA) to evaluate the healing of tooth extraction sites in further three months.

\section{Material Placement}

After appropriate bone healing, infiltration anesthesia comprising of $3.6 \mathrm{ml}$ Lidocain (Darou pakhsh pharmaceutical. Mfg. Co., Tehran, Iran) was derived in the mucobuccal fold. Linear incision was prepared from molar to anterior segment and full thickness mucoperiosteal flap was elevated by a mucoperiosteal elevator. Four defects with $5 \mathrm{~mm}$ depth and $5 \mathrm{~mm}$ diameter in each quadrant (16 defects in each dog) were prepared by trephine \#5 surgically. Two of the defects were on the crestal ridge and two others on the buccal surface of the ridge. Then, these 16 defects were randomly filled by following four Scaffolds separately:

1. Bioglass (BG) Scaffold (Novabone, Alachua, USA)

2. Demineralized bone matrix (DBM) Scaffold (BioHorizons' Grafton, Birmingham)

3. Forstrite (FR) Scaffold (New nano, Isfahan University of Technology, Isfahan, Iran)

4. Control group

The above materials' blocks according to size of defects were prepared and rinsed with distilled water according to the manufacturers' instructions. Then all the defects were covered by a non-resorbable membrane (PTFE Whatman, Kent, UK).

\section{Follow-up}

The dogs were kept in the animal house keeping of faculty under consideration of a vet and they were sacrificed in 4 time intervals $(15,30,45$ and 60 days, each dog at each time point). A lethal injection of $40 \mathrm{ml}$ Pentobarbital Sodium at $100 \mathrm{mg} / \mathrm{ml}$ in $290 \mathrm{gr} / 1000 \mathrm{ml}$ Spiritus Fortis, $100 \mathrm{mg} / \mathrm{kg}$ was given to each of the dogs in scheduled time intervals. All 16 samples were extracted using trephine \#8 with sufficient amount of surrounding bone. These procedures were also done in 30, 45 and 60 days after the surgery.

\section{Histological Analysis}

Extracted specimens were kept in glutaraldehyde solution for 6 hours. Four longitudinal ground sections (totally 16 samples for each biomaterial in each interval) were prepared from each defect by using Microtome (Accutom-50, Stuers, Copenhagen, Denmark). The 
Table 1: The mean regenerated lamellar and woven bone in different time intervals

\begin{tabular}{|c|c|c|c|c|c|c|c|}
\hline \multirow[b]{2}{*}{ Day } & \multirow[b]{2}{*}{ Biomaterial } & \multicolumn{3}{|c|}{ Lamellar bone } & \multicolumn{3}{|c|}{ Woven bone } \\
\hline & & Mean (SD) & Upper bound & Lower bound & Mean (SD) & Upper bound & Lower bound \\
\hline \multirow[t]{4}{*}{15} & $B G$ & $24.84(4.26)$ & 27.11 & 22.56 & $15.25(1.35)$ & 15.97 & 14.25 \\
\hline & DBM & $29.71(7.94)$ & 33.95 & 25.48 & $15.00(1.14)$ & 15.60 & 14.39 \\
\hline & FR & $25.21(3.83)$ & 27.26 & 23.17 & $15.87(0.82)$ & 16.31 & 15.43 \\
\hline & Control & $21.59(0.66)$ & 21.94 & 21.24 & $15.17(0.50)$ & 15.54 & 15.10 \\
\hline \multirow[t]{4}{*}{30} & $B G$ & $21.21(0.94)$ & 22.72 & 19.71 & $16.59(1.42)$ & 17.35 & 15.83 \\
\hline & DBM & $21.46(1.96)$ & 22.51 & 20.42 & $17.93(3.08)$ & 19.57 & 16.29 \\
\hline & FR & $26.56(6.97)$ & 30.28 & 22.84 & $18.28(2.35)$ & 19.53 & 17.02 \\
\hline & Control & $22.37(3.44)$ & 24.20 & 20.54 & $16.50(0.70)$ & 16.87 & 16.12 \\
\hline \multirow[t]{4}{*}{45} & $B G$ & $24.28(4.01)$ & 26.41 & 22.14 & $16.68(1.66)$ & 17.57 & 13.80 \\
\hline & DBM & $23.71(2.16)$ & 24.87 & 22.56 & $17.25(1.12)$ & 17.84 & 16.65 \\
\hline & FR & $25.21(3.27)$ & 26.96 & 23.47 & $17.37(1.24)$ & 18.03 & 15.71 \\
\hline & Control & $24.51(2.75)$ & 25.27 & 24.34 & $16.81(1.64)$ & 17.68 & 15.93 \\
\hline \multirow[t]{4}{*}{60} & BG & $22.65(2.76)$ & 24.12 & 21.18 & $15.06(1.43)$ & 15.82 & 14.29 \\
\hline & DBM & $21.12(1.16)$ & 21.74 & 20.50 & $15.00(1.06)$ & 15.56 & 14.43 \\
\hline & FR & $26.65(4.51)$ & 29.06 & 24.24 & $15.33(1.30)$ & 17.03 & 15.71 \\
\hline & Control & $23.43(5.26)$ & 26.24 & 22.63 & $14.78(2.48)$ & 16.45 & 13.82 \\
\hline
\end{tabular}

Table 2: Comparisons of regenerated lamellar and woven bone in different time intervals

\begin{tabular}{|c|c|c|c|c|}
\hline \multirow{2}{*}{$\frac{\text { Day }}{15}$} & \multicolumn{2}{|c|}{$\begin{array}{l}\text { Comparing } \\
\text { biomaterials }\end{array}$} & \multirow{2}{*}{$\begin{array}{l}\text { Lamellar bone } \\
1.00\end{array}$} & \multirow{2}{*}{$\begin{array}{l}\text { Woven bone } \\
0.99\end{array}$} \\
\hline & FR & $B G$ & & \\
\hline & & DBM & 0.11 & 0.97 \\
\hline & & Control & 0.43 & 1.00 \\
\hline & DBM & $B G$ & 0.55 & 1.00 \\
\hline & & Control & 0.001 & 1.00 \\
\hline & BG & Control & 0.63 & 1.00 \\
\hline \multirow[t]{6}{*}{30} & FR & BG & 0.026 & 0.18 \\
\hline & & DBM & 0.032 & 1.00 \\
\hline & & Control & 0.19 & 0.13 \\
\hline & DBM & $B G$ & 1.00 & 0.56 \\
\hline & & Control & 1.00 & 0.44 \\
\hline & BG & Control & 0.97 & 1.00 \\
\hline \multirow[t]{6}{*}{45} & FR & BG & 1.00 & 0.88 \\
\hline & & DBM & 1.00 & 0.97 \\
\hline & & Control & 0.84 & 1.00 \\
\hline & DBM & BG & 1.00 & 0.96 \\
\hline & & Control & 0.98 & 1.00 \\
\hline & BG & Control & 0.99 & 0.79 \\
\hline \multirow[t]{6}{*}{60} & FR & $B G$ & 0.26 & 1.00 \\
\hline & & DBM & 0.012 & 1.00 \\
\hline & & Control & 0.018 & 0.92 \\
\hline & DBM & BG & 0.99 & 1.00 \\
\hline & & Control & 0.36 & 1.00 \\
\hline & $B G$ & Control & 0.84 & 1.00 \\
\hline
\end{tabular}

samples were stained by Hematoxylin and Eosin stain (H\&E) and mounted on the histological lams. All stained specimens were investigated under optical microscope (40× magnification) (Ziess, Germany) and percentage of different types of regenerated bones (lamellar and woven) and connective tissue were recorded. The cross sections of specimens were surveyed by Adobe Photoshope 7.0 (San Jose CA.) and the amount of the regenerated bone was re-evaluated to confirm data. Data analysis were carried out by one-way ANOVA and post hoc using SPSS software version. 15 at significant level of 0.05 .

\section{RESULTS}

Table 1 represents the descriptive analysis of regenerated lamellar and woven bones induced by biomaterials and Table 2 demonstrates comparisons between biomaterials in each time intervals.

Day 15: Based on the results, DBM Scaffold induced the highest amount of lamellar bone (29.71 \pm 7.94$)$ and FR Scaffold caused the highest amount of regenerated woven bone $(15.87 \pm 0.82)$.

The results of comparison showed that only DBM Scaffold provided significant difference with the control group ( $\mathrm{p}=0.001)$.

Day 30: In this interval, although the amount of regenerated lamellar bone was approximate to each other in control, DBM and BG Scaffold (22.37 $\pm 3.44 ; 21.46 \pm 1.96$; $21.21 \pm 0.96)$, the FR Scaffold provided the highest amount of lamellar (29.71 \pm 7.94$)$ and woven bone (18.28 \pm 2.35$)$.

Also, FR Scaffold showed significant difference with BG $(p=0.026)$ and DBM Scaffolds $(p=0.032)$ in regenerated lamellar bone.

Day 45: FR Scaffold caused the highest amount of lamellar (25.21 \pm 3.27$)$ and woven $(17.37 \pm 1.24)$ regenerated bone. The lowest lamellar and woven bone was observed in DBM Scaffold (23.71 \pm 2.16$)$ and control (16.81 \pm 1.64$)$ groups.

Day 60: Based on analyzed results, FR Scaffold induced the highest level of lamellar $(26.65 \pm 4.51)$ and woven $(15.33 \pm 1.30)$ regenerated bones; also FR Scaffold showed significant difference with DBM Scaffold $(p=0.018)$ and control $(p=0.012)$ groups in amounts of lamellar bone regeneration. 


\section{DISCUSSION}

Emerging cell-based tissue engineering technique currently has offered great fortune to meet the clinical need for bone substitutes. There has been growing interest in using 3D Scaffolds for supporting bone regeneration. ${ }^{6,27-29}$

An appropriate Scaffold must have a suitable interconnected pore network which can make migration and proliferation of osteoblasts cells more. ${ }^{6,22}$ In the present study, the use of Forsterite seems to have promising results compared to other Scaffolds in repairing bone defects.

FR is a nanocrystalat bioceramic made of Talc, Alumina, and Magnesium Carbonat with not only lots of macropores, but also plentiful micropores (on the scale of 1-10 nm) on the macroporous walls. The FR Scaffold provides the most suitable morphology with $30 \% \mathrm{Wt}$ and shows steady structure, ${ }^{22}$ while the nano BG with its high biocompatibility, as Hajialian $\mathrm{H}$ et al claimed, has only $7.5 \% \mathrm{Wt}^{30}$

As the result showed, the FR Scaffold made the highest generation of lamellar bones in days 30,45 and 60; and the highest level of woven bone in all the intervals. Maybe it is needed to mention that in the initial stage of bone healing, the matrix proteins can be attracted by Nano-size granules then a vascular rich protein matrix would be formed. So the osteogenesis happens on this matrix and the final bone is regenerated. Since nano scale structures provide a larger surface area, the amount of attracted proteins would be much more increased. This can be an explanation why the use of nano materials (FR Scaffold) can enhance the bone regeneration capacity compared to micros (DBM and BG Scaffold). Also these larger surface areas pretend as biological materials. ${ }^{31}$ Zhou $\mathrm{Y}$ et al claimed that different ions including $\mathrm{Mg}^{2+}$ and $\mathrm{Si}^{4+}$, specially in crystalized form (like FR structure), shows a little cytotoxicity and significant promotion of regeneration. ${ }^{32}$ Also nanoparticles accelerate the substitution of biomaterials by vital bone $\mathrm{e}^{33}$ and can induce the osteogenic differentiation of stem cells. ${ }^{34} \mathrm{All}$ of these mentioned capabilities can explain the significant difference which were observed between FR and DBM $(p=0.032)$, and BG ( $p=0.026)$ Scaffolds after 30 days. The histopathology of the samples after 15 and 30 days in Figures 1 and 2.

To respect to Helsinki declaration, we limited our samples to four dogs but tried to compensate with higher number of defects. As each dog was designated for one interval and biology of each dog might be different from another one, comparing regenerated bone among them might not be logical. For instance, considering lower amount of regenerated woven bone in day 60th
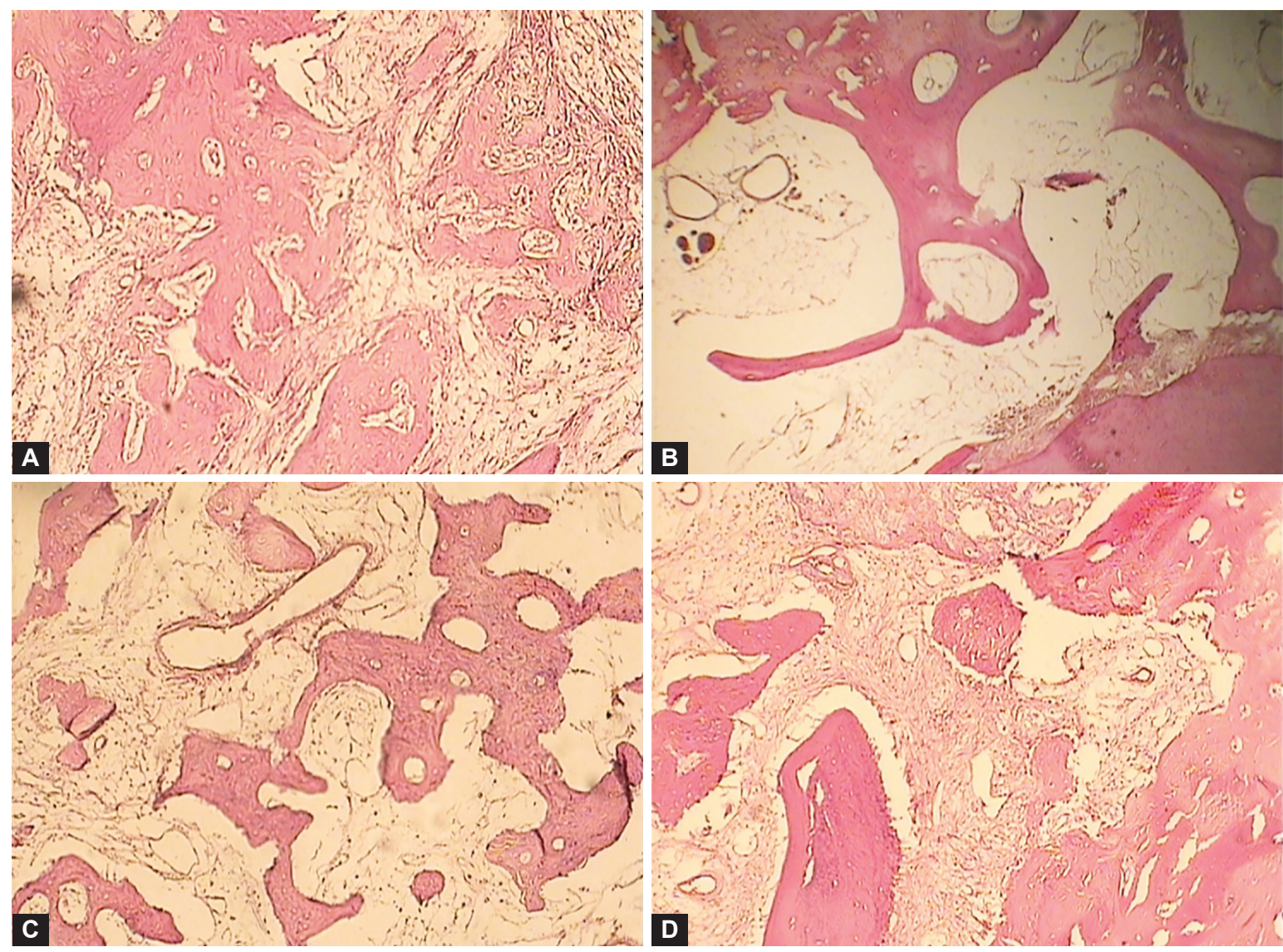

Figs $1 \mathrm{~A}$ to $\mathrm{D}$ : Histopathology of the sample after 15 days $A(B G), B(C), C(F r)$ and $D(B D M)$ 

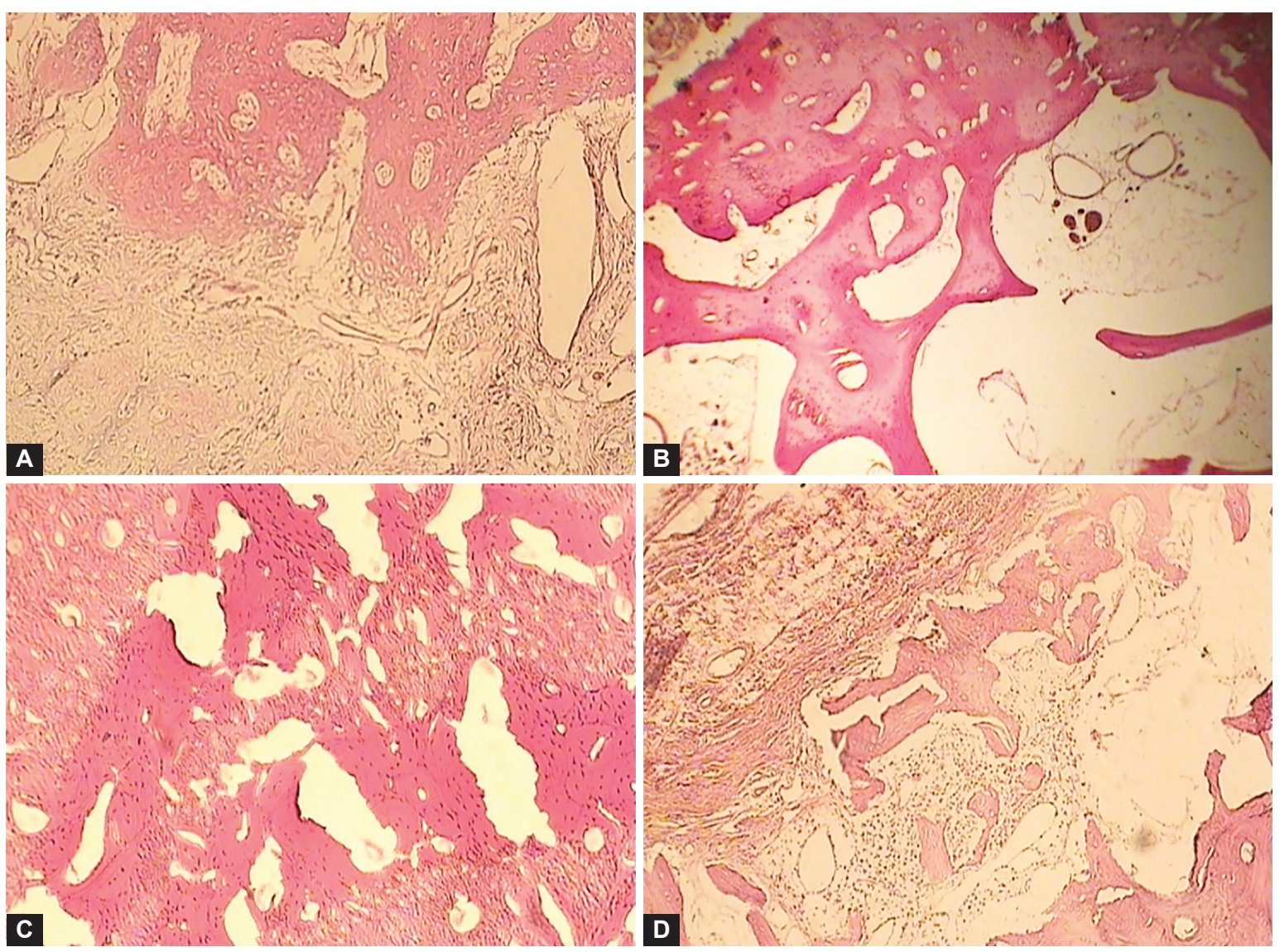

Figs 2A to D: Histopathology of the sample after 30 days A (BDM), B (C), C (BG) and D (Fr)

in comparison with day 45 th is not suggested. Also it is stated that new bone formation around the materials is influenced by their location within the bone. ${ }^{35}$

The BG Scaffold did not show significant differences with other groups specially the controls $(p>0.05)$; and following the recommendation of using nano BG Scaffold instead of microporous BG Scaffold ${ }^{36}$ is suggested.

\section{CONCLUSION}

By considering limitations of this study, the FR Scaffold showed the highest amount of bone regeneration specially after 30 days. We recommend paying more attention to this material as a 3D scaffold as a biomaterial for regenerating bone, but it is better to be compared with other nano type materials in future studies.

\section{REFERENCES}

1. Li LJ, Liu N, Shi JG, Liu Q, Jia LS, Yuan W. Osteogenic scaffolds for bone reconstruction. Biores Open Access 2012;1(3):137-144.

2. El-Gendy R, Yang XB, Newby PJ, Boccaccini AR, Kirkham J. Osteogenic differentiation of human dental pulp stromal cells on 45 S5 bioglass(R) based scaffolds in vitro and in vivo. Tissue Eng Part A 2013;19(5-6):707-715.

3. Chantarawaratit P, Sangvanich P, Banlunara W, Soontornvipart K, Acemannan TP. Sponges stimulate alveolar bone, cementum and periodontal ligament regeneration in a canine class II furcation defect model. J Periodontal Res 2014; 49(2):164-178.

4. Zhang D, George OJ, Petersen KM, Jimenez-Vergara AC, Hahn MS, Grunlan MA. A bioactive 'self-fitting' shape memory polymer scaffold with potential to treat craniomaxillo facial bone defects. Acta Biomater 2014;24(11):1-9.

5. Cottrell DA, Wolford LM. Long-term evaluation of the use of coralline hydroxyapatite in orthognathic surgery. J Oral Maxillofac Surg 1998;56(8):935-941.

6. Jones JR, Lin S, Yue S, Lee PD, Hanna JV, Smith ME, et al. Bioactive glass scaffolds for bone regeneration and their hierarchical characterisation. Proc Inst Mech Eng H 2010; 224(12):1373-1387.

7. Kweon H, Lee KG, Chae CH, Balazsi C, Min SK, Kim JY, et al. Development of nano-hydroxyapatite graft with silk fibroin scaffold as a new bone substitute. J Oral Maxillofac Surg 2011;69(6):1578-1586.

8. Valimaki VV, Aro HT. Molecular basis for action of bioactive glasses as bone graft substitute. Scand J Surg 2006;95(2): 95-102.

9. Sculean A, Barbe G, Chiantella GC, Arweiler NB, Berakdar M, Brecx M. Clinical evaluation of an enamel matrix protein derivative combined with a bioactive glass for the treatment of intrabony periodontal defects in humans. J Periodontol 2002;73(4):401-408

10. Henkel KO, Gerber T, Lenz S, Gundlach KK, Bienengraber V. Macroscopical, histological, and morphometric studies of porous bone-replacement materials in minipigs 8 months after implantation. Oral Surg Oral Med Oral Pathol Oral Radiol Endod 2006;102(5):606-613. 
11. Le Guehennec L, Layrolle P, Daculsi G. A review of bioceramics and fibrin sealant. Eur Cell Mater 2004;8:1-10.

12. Saino E, Grandi S, Quartarone E, Maliardi V, Galli D, Bloise $\mathrm{N}$, et al. In vitro calcified matrix deposition by human osteoblasts onto a zinc-containing bioactive glass. Eur Cell Mater 2011;21:59-72.

13. Brandao SM, Schellini SA, Moraes AD, Padovani CR, Pellizzon $\mathrm{CH}$, Peitl $\mathrm{O}$, et al. Biocompatibility analysis of bioglass(R) $45 S 5$ and biosilicate(R) implants in the rabbit eviscerated socket. Orbit 2012;31(3):143-149.

14. Chitsazi MT, Shirmohammadi A, Faramarzie M, Pourabbas $\mathrm{R}$, Rostamzadeh A. A clinical comparison of nano-crystalline hydroxyapatite (Ostim) and autogenous bone graft in the treatment of periodontal intrabony defects. Med Oral Patol Oral Cir Bucal 2011;16(3):448-453.

15. Stavropoulos A, Sima C, Sima A, Nyengaard J, Karring T, Sculean A. Histological evaluation of healing after transalveolar maxillary sinus augmentation with bioglass and autogenous bone. Clin Oral Implants Res 2012;23(1):125-131.

16. Gatti AM, Simonetti LA, Monari E, Guidi S, Greenspan D. Bone augmentation with bioactive glass in three cases of dental implant placement. J Biomater Appl 2006;20(4):325-339.

17. Su J, Cao L, Yu B, Song S, Liu X, Wang Z, et al. Composite scaffolds of mesoporous bioactive glass and polyamide for bone repair. Int J Nanomedicine 2012;7:2547-2555.

18. Jones JR. Review of bioactive glass: from Hench to hybrids. Acta Biomater 2013;9(1):4457-4486.

19. Chen QZ, Efthymiou A, Salih V, Boccaccini AR. Bioglassderived glass-ceramic scaffolds: study of cell proliferation and scaffold degradation in vitro. J Biomed Mater Res A 2008;84(4):1049-1060.

20. Tavangarian REF. Nanostructure effects on the bioactivity of forsterite bioceramic. Materials Letters 2011;65(4):740-743.

21. Tavangariana REF. Synthesis of nanocrystalline forsterite $\left(\mathrm{Mg}_{2} \mathrm{SiO}_{4}\right)$ powder by combined mechanical activation and thermal treatment. Materials Research Bulletin 2011;45(4): 388-391.

22. Mani Diba MHF, M. Kharaziha. Novel forsterite/polycaprolactone nanocomposite scaffold for tissue engineering applications. Materials Letters 2011;65(12):1931-1934.

23. Emadi FTR, Esfahani SIR. Biodegradable and bioactive properties of a novel bone scaffold coated with nanocrystalline bioactive glass for bone tissue engineering. Materials Letters 2010;64(13):1528-1531.

24. Akkouch A, Zhang Z, Rouabhia M. Engineering bone tissue using human dental pulp stem cells and an osteogenic collagen-hydroxyapatite-poly(-lactide-co-\{varepsilon\}caprolactone) scaffold. J Biomater Appl 2013;28(6):922-936.

25. Thakoon Thitiset SD, Bunaprasert T, Leeanansaksiri $\mathrm{W}$, Honsawek S. Development of collagen/demineralized bone powder scaffolds and periosteum-derived cells for bone tissue engineering application. Int J Mol Sci 2013;14(1): 2056-2071.

26. Xia Z, Yu X, Jiang X, Brody HD, Rowe DW, Wei M. Fabrication and characterization of biomimetic collagen-apatite scaffolds with tunable structures for bone tissue engineering. Acta Biomater 2013 Jul;9(7):7308-7319.

27. Deb S, Mandegaran R, Di Silvio L. A porous scaffold for bone tissue engineering/45S5 Bioglass derived porous scaffolds for co-culturing osteoblasts and endothelial cells. J Mater Sci Mater Med 2010;21(3):893-905.

28. Hafezi F, Hosseinnejad F, Fooladi AA, Mafi SM, Amiri A, Nourani MR. Transplantation of nano-bioglass/gelatin scaffold in a non-autogenous setting for bone regeneration in a rabbit ulna. J Mater Sci Mater Med 2012;23(11):2783-2792.

29. Rodenas-Rochina J, Ribelles JL, Lebourg M. Comparative study of PCL-HAp and PCL-bioglass composite scaffolds for bone tissue engineering. J Mater Sci Mater Med 2013;24(5):1293-1308.

30. Hajiali H, Hosseinalipour M, Karbasi S, Shokrgozar MA. The influence of bioglass nanoparticles on the biodegradation and biocompatibility of poly (3-hydroxybutyrate) scaffolds. Int J Artif Organs 2012;35(11):1015-1024.

31. Quinones C LT. Utilization of a bioactive synthetic particulate for periodontal therapy and bone augmentation techniques. Pract Periodont Aesthet Dent 1997;9:1-9.

32. Zhou Y, Li H, Lin K, Zhai W, Gu W, Chang J. Effect of heat treatment on the properties of $\mathrm{SiO}_{2}-\mathrm{CaO}-\mathrm{MgO}-\mathrm{P}_{2} \mathrm{O}_{5}$ bioactive glasses. J Mater Sci Mater Med 2012;23(9):2101-2108.

33. Strietzel FP, Reichart PA, Graf HL. Lateral alveolar ridge augmentation using a synthetic nano-crystalline hydroxyapatite bone substitution material (Ostim): preliminary clinical and histological results. Clin Oral Implants Res 2007;18(6): 743-751.

34. Liu Y, Wang G, Cai Y, Ji H, Zhou G, Zhao X, et al. In vitro effects of nanophase hydroxyapatite particles on proliferation and osteogenic differentiation of bone marrow-derived mesenchymal stem cells. J Biomed Mater Res A 2009;90(4):1083-1091.

35. Azenha MR, Peitl O, Barros VM. Bone response to biosilicates with different crystal phases. Braz Dent J 2010;21(5):383-389.

36. Shalumon KT, Sowmya S, Sathish D, Chennazhi KP, Nair SV, Jayakumar R. Effect of incorporation of nanoscale bioactive glass and hydroxyapatite in PCL/chitosan nanofibers for bone and periodontal tissue engineering. J Biomed Nanotechnol 2013;9(3):430-440. 